\title{
A OPÇÃO PELOS CURSOS DO ENSINO MÉDIO INTEGRADO
}

\author{
Paula Danyelle Santana de Andrade, Sônia Pinto de Albuquerque Melo \\ E-mail: pauladanyeli@hotmail.com, sonia.melo@ifs.edu.br \\ Instituto Federal de Educação, Ciência e Tecnologia de Sergipe \\ DOI: 10.15628/rbept.2020.9895
}

Artigo submetido em: abr./2020 e aceito em: maio/2020

\begin{abstract}
RESUMO
Os Institutos Federais de Educação, Ciência e Tecnologia têm ocupado um papel importante na oferta do Ensino Médio Integrado (EMI). Segundo Ciavatta (2014), Ramos (2010) e Moura (2010), o EMI tratase de uma possibilidade de superação da dualidade educacional historicamente constituída no Brasil. Destarte, buscou-se compreender sobre a importância da escolha consciente dos estudantes acerca dos cursos técnicos integrados. Assim, foi feita uma pesquisa bibliográfica sobre o histórico da trajetória desses institutos, tratando da relação entre a educação básica e a profissional. Trouxe-se a concepção de EMI, demonstrando o papel que esse formato de ensino tem para a sociedade. Posteriormente, tratou-se sobre a importância de uma escolha consciente pelos estudantes ao optarem por um curso do EMI. Com isso, verificamos que muitos os alunos optam por ingressar nos técnicos integrados ao ensino médio por influências externas, muitas vezes, distanciando-se de seus projetos de futuro.
\end{abstract}

Palavras-chave: Ensino Médio Integrado. Institutos Federais. Estudantes.

\section{THE OPTION FOR INTEGRATED HIGH SCHOOL COURSES}

\begin{abstract}
The Federal Institutes of Education, Science and Technology have played an important role in the offer of Integrated High School (EMI). According to Ciavatta (2014), Ramos (2010) and Moura (2010), EMI is a possibility to overcome the educational duality historically constituted in the country. Thus, we sought to understand the importance of students' conscious choice about integrated technical courses. Thus, a bibliographic search was made on the history of the trajectory of these institutes, dealing with the relationship between basic and professional education. The concept of EMI was brought up, demonstrating the role that this teaching format has for society. Subsequently, it was about the importance of conscious choice by students when choosing an EMI course. Thus, we found that many students choose to join technicians integrated into high school by external influences, often distancing themselves from their future projects.
\end{abstract}

Keywords: Integrated High School. Federal Institutes. Students. 


\section{INTRODUÇÃO}

Com a promulgação da Lei $n^{\circ} 11.892 / 2008$, foi instituída a Rede Federal de Educação Profissional Científica e Tecnológica e foram criados os Institutos Federais de Educação, Ciência e Tecnologia (IF). Segundo a Secretaria de Educação Profissional e Tecnológica (Setec), do Ministério da Educação, o foco dessas instituições de ensino é voltado para a justiça social, competitividade econômica, a equidade e a geração de novas tecnologias (BRASIL/MEC, 2008).

A referida lei classifica os Institutos Federais, em seu art. $2^{\circ}$, como organizações especializadas em ofertar a educação profissional e tecnológica nas diversas modalidades de ensino, com a junção de conhecimentos técnicos e tecnológicos com as práticas pedagógicas (BRASIL, 2008). Além disso, atuam em todos os níveis e modalidades da educação profissional, buscam o desenvolvimento integral do indivíduo e ofertam:

[...] educação básica, principalmente em cursos de ensino médio integrado à educação profissional técnica de nível médio; ensino técnico em geral; cursos superiores de tecnologia, licenciatura e bacharelado em áreas em que a ciência e a tecnologia são componentes determinantes, em particular as engenharias, bem como programas de pós-graducação latu e stricto sensu, sem deixar de assegurar a formação inicial e continuada do trabalhador e dos futuros trabalhadores. (BRASIL/MEC, 2008, p. 27).

$\mathrm{Na}$ Lei n. 11.892/2008, pode-se verificar que a proposta dos IF busca a superação da dualidade educacional existente, ao propor uma educação que possibilite ao indivíduo o desenvolvimento dos conhecimentos científicos e tecnológicos, de modo que estimule a emancipação humana. Assim, é importante destacar os incisos IV e V do art. $7^{\circ}$, a saber (BRASIL, 2008)

\footnotetext{
IV - desenvolver atividades de extensão de acordo com os princípios e finalidades da educação profissional e tecnológica, em articulação com o mundo do trabalho e os segmentos sociais, e com ênfase na produção, desenvolvimento e difusão de conhecimentos científicos e tecnológicos; $\mathrm{V}$ - estimular e apoiar processos educativos que levem à geração de trabalho e renda e à emancipação do cidadão na perspectiva do desenvolvimento socioeconômico local e regional.
}

Para autores como Ciavatta (2014), Ramos (2010) e Moura (2010), integrar o núcleo comum ao núcleo profissional pode contribuir para a superação da dualidade educacional historicamente constituída no Brasil. Na concepção desses autores, os 
jovens terão condições de atuar com autonomia e criticidade nos diversos setores de suas vidas.

Ciavatta (2014) não trata da formação integrada simplesmente como uma articulação entre a educação básica e a profissional, mas relaciona-a à concepção de formação politécnica. A autora esclarece que essa formação objetiva:

\begin{abstract}
[..] tornar íntegro, inteiro, o ser humano dividido pela divisão social do trabalho entre a ação de executar e a ação de pensar, dirigir ou planejar. Trata-se de superar a redução da preparação para o trabalho ao seu aspecto simplificado, escoimado dos conhecimentos que estão na sua gênese científicotecnológica e na sua apropriação histórico-social. (CIAVATTA, 2012, p. 84).
\end{abstract}

Chagas, Martins e Barbosa (2019) mencionam que a proposta de integração entre formação básica e a profissional nos institutos vai em direção a um modelo de educação que promove a Formação Humana Integral. Contudo, na prática, conforme os autores, ainda existe um distanciamento entre elas, principalmente, ao sobreporse o currículo das disciplinas básicas ao das técnicas. "E isso pode apresentar consequências nos motivos que levam os estudantes a procurarem os IF, assim como no que poderão realizar em suas vidas após concluírem o EMI". (CHAGAS; MARTINS; BARBOSA, 2019, p. 569).

Ramos (2014a) esclarece que a etapa do ensino médio na vida dos estudantes é de suma importância, uma vez que se trata do momento do desenvolvimento educacional, em que se deparam com a perspectiva do seu futuro profissional. Nesta fase, "a relação entre ciência, conhecimento científico e produção, modo de produção da existência, processo econômico, de geração de riqueza, distribuição de riqueza e trabalho, divisão social do trabalho, se manifestam". (RAMOS, 2014a, p. 17).

Assim, no presente artigo pretende-se compreender acerca da necessidade de que os estudantes que ingressam nos cursos técnicos integrados ao ensino médio façam sua escolha de forma consciente, de modo que possam prosseguir com seus projetos de futuro. Para isso, foi realizada uma pesquisa bibliográfica acerca da temática apresentada. $O$ texto foi subdividido em mais 3 seções, além da presente introdução. Na primeira, será apresentado um breve histórico da trajetória dos Institutos Federais, relacionando-a à educação básica e à profissional. Na segunda, será abordado acerca da concepção de EMI. No terceiro, será tratado sobre a importância de uma escolha consciente pelos estudantes. Por fim, será feita uma conclusão dos aspectos discutidos. 


\section{A TRAJETÓRIA DOS INSTITUTOS FEDERAIS DE EDUCAÇÃO CIÊNCIA E TECNOLOGIA}

A constituição dos Institutos Federais ocorreu simultaneamente com a história da Rede de Educação Profissional e Tecnológica do país, contribuindo para a relação entre a educação e o trabalho ao longo das décadas.

Foi em 1909 que surgiram as primeiras instituições que deram origem ao que hoje se conhece como Institutos Federais de Educação, Ciência e Tecnologia. O presidente da época, Nilo Peçanha, por meio do Decreto $n^{\circ} 7.566 / 1909$, instituiu nas capitais dos Estados as Escolas de Aprendizes e Artífices. O objetivo desse normativo era promover o ensino profissional primário e gratuito aos filhos dos menos favorecidos e conhecimentos técnicos essenciais à aprendizagem de um ofício. (BRASIL, 1909).

Na década de 1930, houve modificações na conjuntura socioeconômica e política do país. Foi criado o primeiro ministério voltado à esfera educacional, o Ministério da Educação e Saúde Pública. (MOURA, 2010). Em 1931, ocorreu a Reforma de Campus, ratificada pela Constituição de 1934, por meio da qual o governo federal assumiu um compromisso com o ensino secundário ao conferir-lhe conteúdo e seriação particular. Em 1937, as Escolas de Aprendizes Artífices foram transformadas em Liceus, com o intuito de ofertar o ensino profissional em seus diversos ramos e graus.

Com o advento da Segunda Guerra Mundial, houve aumento na demanda em torno da área industrial, bem como ocorreram mudanças nas áreas urbanas do país, o que exigiu um maior investimento na educação profissional. Com isso, no período Vargas, o ministro da Educação, Gustavo Capanema, promoveu uma série de transformações no sistema educacional brasileiro, instituídas por meio das Leis Orgânicas do Ensino. Todo esse conjunto de leis, promulgado nos anos 1940, é considerado por Moura (2010) como de grande importância no contexto educacional, mais especificamente, o profissional. Isso porque, foram estabelecidos normativos próprios para formação profissional em cada setor da economia e a formação de docentes do nível médio.

Dentre essas leis, destaque-se o Decreto-Lei $n^{\circ} 4.127$, de 25 de fevereiro de 1942, publicado com o objetivo de formar as bases da organização da rede federal de instituições que poderiam atuar no ensino industrial. O novo decreto extinguiu os Liceus, considerou como instituições pertencentes a essa rede, as escolas técnicas, as industriais, as artesanais e as de aprendizagem. (BRASIL, 1942). Já em 1946, o Decreto-Lei no 9.613 foi instaurado para estabelecer as bases de organização e de regime do ensino agrícola. A nova Lei Orgânica do Ensino Agrícola estabelecia três tipos de escolas: as de iniciação agrícola, as agrícolas e as agrotécnicas. (BRASIL, 1946).

Foi na década de 1950, para promover a equivalência entre a educação secundária e a profissional, que se permitiu aos estudantes tanto do ensino básico 
quanto do técnico o ingresso nas instituições de ensino superior. Sua implementação ocorreu, de forma integral, com a promulgação da primeira Lei de Diretrizes e Bases da Educação Nacional (LDBEN). (FRIGOTTO; CIAVATTA; RAMOS, 2012). Todavia, na prática, ainda se destinava a uns uma formação direcionada à preparação para os processos de seleção desse nível de ensino, e a outros, uma educação em que predominavam os conteúdos mais específicos, voltados para as necessidades do mercado de trabalho. (MOURA, 2010).

Sobre os efeitos da promulgação da primeira LDBEN, faz-se necessário mencionar, também, que a "Escola Agrícola Benjamin Constant" passou a denominarse "Colégio Agrícola", onde era ofertado o $2^{\circ}$ ciclo do colegial e garantia-se um diploma técnico aos que concluíssem o curso.

Em 1959, as instituições voltadas ao ensino industrial passaram a ter personalidade jurídica própria e autonomia didática, administrativa, técnica e financeira (BRASIL, 1959). Ainda nesse ano, as Escolas Industriais e Técnicas receberam a nomenclatura de Escolas Técnicas Federais (ETF) e foi estabelecido que elas iriam compor a rede federal de ensino técnico, sob a condição de autarquias. (RAMOS, 2014b).

O período compreendido entre 1968 a 1973 ficou conhecido como o momento histórico do país, o "milagre econômico". De acordo com Moura (2010), o progresso econômico foi construído em cima de um endividamento externo, que objetivava intensificar a industrialização do país. Nessa conjuntura, cresceu-se a demanda por mão de obra qualificada, mais precisamente, os técnicos de nível médio. Como solução, o governo recorreu ao investimento em formação profissionalizante da população, ainda no $2^{\circ}$ grau, a fim de dar condições a sua inserção no mercado de trabalho.

A demanda por mão de obra qualificada para atender às demandas do mercado de trabalho impulsionou a Reforma do Ensino de $1^{\circ}$ e $2^{\circ}$, instaurada pela Lei $n^{\circ}$ 5.692/1971. Por meio dessa reforma, ficou estabelecida a obrigatoriedade da preparação para o trabalho na etapa do $2^{\circ}$ grau. Além disso, deixou estabelecido o predomínio da formação profissional sobre a educação geral. (BRASIL, 1971). Segundo Moura (2010), tal obrigatoriedade atingiu apenas as escolas públicas, já a maior parte das privadas mantiveram-se voltadas para a formação básica. Ele ainda esclarece que as escolas estaduais, em virtude da falta de ampliação da carga horária do $2^{\circ}$ grau, para que as matérias do ensino profissional fossem incluídas, tiveram que diminuir a carga horária da formação básica. Isso trouxe para a educação pública estadual um aspecto meramente instrumental, que não possibilitava aos estudantes a aquisição de conhecimentos com maior complexidade, inerentes aos aspectos do trabalho.

Neste contexto, para Ramos (2014a), as ETF começaram a ser procuradas por outros estabelecimentos de ensino para fins de convênio, por oferecerem ensino profissionalizante de qualidade. Isso viabilizava àquelas instituições que ofereciam o ensino básico, que disponibilizassem também o segmento técnico, conforme ordenava a Lei $\mathrm{n}^{\circ}$ 5.692/1971. A autora destaca que isso impulsionou 0 
desenvolvimento da formação constituída no âmbito dessas escolas e acentuou sua qualidade do ensino. Com isso, passaram a ser reconhecidas como as mais apropriadas para ofertar o ensino profissionalizante no $2^{\circ}$ grau direcionado para habilitações específicas. De acordo com Moura (2010, p. 68), esse destaque tanto das Escolas Técnicas quanto das Agrotécnicas Federais, só foi possível, em decorrência de um "financiamento adequado e corpo docente especializado".

A Lei $n^{\circ} 6.545 / 1978$ foi promulgada, por meio da qual Escolas Técnicas Federais de Minas Gerais, do Paraná e Celso Suckow da Fonseca transformaram-se em Centros Federais de Educação Tecnológica. Essas instituições não ofertariam apenas os cursos técnicos, mas passariam a ministrar também os cursos de graduação, "ministrando a Engenharia Industrial, os cursos tecnólogos e as licenciaturas voltadas para a formação de professores do ensino técnico e dos cursos de tecnólogos, além da extensão e da pós-graduação lato sensu". (FRIGOTTO; CIAVATTA; RAMOS, 2012, p. 47).

Em 1982, extinguiu-se a obrigatoriedade da profissionalização no ensino do $2^{\circ}$ grau, por força da Lei $n^{\circ} 7.044 / 82$. (BRASIL, 1982). Como relata Moura (2010), no período entre o final dos anos 80 e início dos anos 90, o que se percebia era uma redução significativa do $2^{\circ}$ grau profissionalizante, com exceção das Escolas Técnicas e das Agrotécnicas, bem como algumas poucas escolas estaduais.

Com a implementação do Programa de Expansão e Melhoria do Ensino Técnico (PROTEC), em 1986, foram criadas as Unidades de Ensino Descentralizadas (Uned), as quais vinculavam-se a uma "escola mãe", que poderia ser uma Escola Técnica, Agrotécnica ou um Centro Federal de Educação Tecnológica (Cefet). Como resultado, em 1993, foram inauguradas 11 Uneds e outras 36 estavam sendo construídas (RAMOS, 2014b).

As Escolas Técnicas começaram a ser transformadas em Cefet, em virtude da Lei $n^{\circ}$ 8.948/1994, que instituiu o Sistema Nacional de Educação Tecnológica. O objetivo disto era distanciar a possibilidade de mudança dessas escolas para o sistema estadual ou para o Serviço Nacional de Aprendizagem Industrial (Senai), ou mesmo para a privatização. A cefetização das escolas técnicas foi efetivada, com decreto específico para cada uma, depois da aprovação dos projetos institucionais elaborados pelas escolas, pelo Ministro de Estado da Educação e dos Desporto (RAMOS, 2014b).

No final dos anos 1980, passou-se a discutir concepção de politecnia, com o propósito de alcançar a superação da dualidade estrutural da educação no país, para fins de elaboração do primeiro projeto da nova Lei de Diretrizes e Bases da Educação (LDB). Com isso, ao pensar-se em um modelo que propusesse a superação da dicotomia existente entre a formação básica e a técnica, e que garantisse ao indivíduo uma formação integral, criticava-se o ensino técnico de $2^{\circ}$ grau estabelecido pela Lei $n^{\circ} 5.692 / 71$, que visava a predominância da segunda sobre a primeira. (FRIGOTTO; CIAVATTA; RAMOS, 2012). 
Para Ramos (2017), a politecnia objetiva oportunizar aos educandos a concepção dos elementos caracterizados como "científicos", "tecnológicos" e "sóciohistóricos" relacionados à produção. Como consequência, conforme explana a autora, caminhar-se-ia em direção a uma formação humana mais completa. Para a autora, o objetivo da formação profissionalizante não se embasaria simplesmente "pelos interesses do mercado, mas constituir-se-ia numa possibilidade a mais para os estudantes na construção de seus projetos de vida, socialmente determinados, culminada com uma formação ampla e integral" (RAMOS, 2014b, p. 38-39).

Após as discussões em torno da elaboração dos projetos que dariam origem à LDB, foi promulgada a Lei $n^{\circ} 9.394 / 1996$. A referida lei trouxe em seu teor uma imprecisão ao que de fato pretendia, não ficou claro se a articulação entre a educação profissional e o ensino regular estaria impulsionando também a integração dessas formas de ensino. A esse respeito, Moura (2010) aponta um aspecto importante que caracteriza a ambiguidade que essa norma traz em seu conteúdo. De acordo com o autor, esse instrumento jurídico tratou do ensino médio e da formação profissional em dois capítulos distintos. Enquanto o ensino médio era enquadrado como uma das etapas da educação básica, a educação profissional era discutida de forma a parte. Ele destaca que a educação brasileira, conforme consta na letra da lei, seria composta apenas pela educação básica e pela superior. Isso só demonstra que a educação profissional não compunha a "educação regular brasileira". Na verdade, ela era tratada separadamente. Nas palavras de Moura (2010, p. 71), a mesma era vista como uma "modalidade".

Ainda na década de 1990, foi publicado o Decreto $n^{\circ} 2.208 / 1997$, que visava a regulamentar o $\S 2 \circ$ do art. 36 e os arts. 39 a 42 da Lei no 9.394/1996. Esse novo decreto estabeleceu, mais precisamente, em seu art. $5^{\circ}$, que a educação profissional trará em sua composição uma organização curricular própria e independente do ensino médio, permitindo-se, inclusive, a oferta de matrículas nas formas concomitante e sequencial. (BRASIL, 1997).

Segundo Ramos (2010), mesmo a LDB tendo trazido a concepção do direito ao acesso à educação profissional, o Decreto $n^{\circ} 2.208 / 97$ desobrigou a oferta e o financiamento pelos sistemas de ensino. Apenas a rede federal de educação tecnológica teve amparo para oferecer modalidade, considerando que possuíam orçamento específico para atendimento a suas funcionalidades.

No âmbito das Instituições Federais de Educação Tecnológica (Ifet), com a Portaria $n^{\circ} 646 / 1997$, estabeleceu-se que, a partir de 1998, as vagas dos cursos técnicos de nível médio seriam reduzidas, não devendo atingir mais do que $50 \%$ (cinquenta por cento) das vagas que seriam ofertadas nos cursos técnicos de nível médio. Com isso, a determinação reduziria a oferta do último nível da educação básica, até que acabasse o vínculo das Ifets com a educação básica. (MOURA, 2010).

No ano de 2003, iniciaram-se novas discussões em torno da reestruturação do ensino médio e da educação profissional, retornando às discussões iniciadas na década de 1980, acerca da educação politécnica. Todavia, diante da conjuntura político e econômica em que o país se encontrava, seria muito complicado implantar 
essa concepção de educação em sua integralidade. Isso porque, os jovens das classes mais baixas, na maioria das vezes, precisavam ingressar no mercado de trabalho, antes mesmo de concluírem uma formação profissional. Assim, o EMI surge como uma proposta que possibilitaria que tais indivíduos tivessem acesso a uma educação básica de qualidade, com base nos preceitos da ciência, tecnologia, cultura e trabalho, que garantisse a aquisição dos conhecimentos científicos que foram produzidos ao longo do tempo. Além disso, o indivíduo teria acesso a uma formação profissional. (MOURA, 2010).

Em 2004, foi publicado o Decreto $n^{\circ} 5.154 / 2004$, o qual revogou o Decreto $n^{\circ}$ 2.208/1997. Por meio do novo decreto, surgiu a possibilidade de articulação entre a educação profissional técnica de nível médio e o ensino médio, na mesma instituição de ensino, com matrícula única para cada estudante (BRASIL, 2004). Neste mesmo ano, as instituições que compunham a rede passaram a ter autonomia para criar e implantar cursos em todos os níveis relativos à educação profissional e tecnológica. $\mathrm{E}$, excepcionalmente, as escolas agrotécnicas foram autorizadas a ofertar os cursos superiores de tecnologia, na graduação (BRASIL/MEC, 2008).

No segundo mandato do presidente Luís Inácio Lula da Silva, a fim de redirecionar, regularizar e integrar os atos da educação profissional técnica de nível médio, de jovens e adultos, e da profissional e tecnológica, foi publicada a Lei $\mathrm{n}^{\circ}$ 11.741/2008. Com a referida lei, foram-se alterados dispositivos da Lei n. 9.394/1996, com o objetivo de incluir o teor do decreto $n^{\circ} 5.154 / 2004$. (RAMOS, 2014b). Isso reacendeu a discussão em torno da dualidade educacional, notadamente, na etapa do ensino médio.

Posteriormente, com a promulgação da Lei $n^{\circ} 11.892 / 2008$, foi instituída a Rede Federal de Educação Profissional Científica e Tecnológica e foram criados 38 (trinta e oito) Institutos Federais de Educação, Ciência e Tecnologia. Os institutos passam a atuar em todos os níveis e modalidades da educação profissional, buscam o desenvolvimento integral do indivíduo e ofertam:

[...] educação básica, principalmente em cursos de ensino médio integrado à educação profissional técnica de nível médio; ensino técnico em geral; cursos superiores de tecnologia, licenciatura e bacharelado em áreas em que a ciência e a tecnologia são componentes determinantes, em particular as engenharias, bem como programas de pós-graducação latu e stricto sensu, sem deixar de assegurar a formação inicial e continuada do trabalhador e dos futuros trabalhadores (BRASIL/MEC, 2008, p. 27).

A lei de criação dos institutos deixa clara a ideia de integração e verticalização da educação básica à educação profissional e à superior. O referido normativo traz como ponto positivo dessa estrutura a otimização da infraestrutura física, dos recursos financeiros, bem como do quadro de pessoal dos institutos (BRASIL, 2008). No tocante à verticalização, é importante destacar o fato de que, com essa nova formatação, exigiu-se do corpo docente uma formação diferenciada, tendo em vista Vol. 2 (2020) 
que esses profissionais, que antes eram enquadrados como professores do $1^{\circ}$ e $2^{\circ}$ graus, passam a fazer parte da carreira de Magistério do Ensino Básico Técnico e Tecnológico. (BARBOSA, 2016).

A criação dos Institutos Federais, segundo o documento elaborado pela SETEC, reafirmou a concepção de política pública da Educação Profissional. Isso porque, a percepção do governo, em relação a esse conceito, iria além do financiamento com orçamento público, pois estaria fundamentada no comprometimento com o todo social, bem como associada a outras políticas, como, por exemplo, as de trabalho e renda, ambiental, social, entre outras. (BRASIL/MEC, 2008).

De acordo com Ramos (2017), em contradição à perspectiva do EMI, em 2017, foi publicada a Lei $n^{\circ} 13.415 / 2017$, também conhecida como a contrarreforma do Ensino Médio, surgida enquanto Medida Provisória $n^{\circ}$ 746/2016. A autora ainda descreve essa reformulação como uma forma da classe hegemônica limitar o acesso à educação básica pública de boa qualidade.

Ramos (2017) também caracteriza essa contrarreforma como uma retomada de outros normativos que traziam a ideia da dualidade educacional e da formação fragmentada. Primeiro, a autora relaciona a divisão do segundo ciclo do ensino secundário entre os cursos clássicos e os científicos, pelo Decreto-Lei $n^{\circ} 4.244 / 1942$, ao que a Lei $n^{\circ} 13.415 / 2017$ aborda sobre os aspectos dos itinerários formativos. Depois, tem-se a questão de transformar a educação específica em um dos itinerários formativos, ao que a autora associa à Lei $n^{\circ} 5.692 / 1971$, quando essa substituiu a carga horária da formação geral pela específica. Por fim, as formas que foram expostas em todo o teor da reforma do ensino médio acabam retomando a conjuntura de separação entre a educação profissional e a básica, como disciplinava o Decreto $n^{\circ} 2.208 / 1997$.

\section{CONCEPÇÃO DE ENSINO MÉDIO INTEGRADO}

Ao tratar sobre o EMI, é importante compreender que ele surgiu como uma possibilidade, para que os estudantes tenham condições de receber uma educação básica de qualidade, com base nos preceitos da ciência, tecnologia, cultura e trabalho, possibilitando a aquisição dos conhecimentos científicos que foram produzidos ao longo do tempo, integrando-se com uma formação profissional (MOURA, 2010).

O EMI não trata de uma simples justaposição ou articulação dos currículos do ensino básico com o ensino profissional, mas corresponde a uma integração entre eles. Conforme bem descreve Ramos (2010, p. 51-52),

Não se trata de somar os currículos e/ou as cargas horárias referentes ao ensino médio e às habilitações profissionais, mas sim de relacionar, internamente à organização curricular e do desenvolvimento do processo de 
ensino-aprendizagem, conhecimentos gerais e específicos; cultura e trabalho; humanismo e tecnologia.

Frigotto, Ciavatta e Ramos (2012) esclarecem que o ensino médio integrado ao técnico não deve ser confundido com o ensino médio politécnico, pois o primeiro deve ser considerado como uma fase transitória, que vem a atender à realidade da maioria dos jovens que estão nessa etapa da vida, os quais necessitam inserir-se no mercado de trabalho. Ramos (2010) aborda sobre isso de forma bem esclarecedora. Para a autora, o EMI é uma "condição social" essencial para a conquista de um ensino médio com uma base unitária e politécnica. Mas, destaca que os sentidos filosóficos e epistemológicos de uma formação politécnica podem estar inseridos no EMI. Neste sentido, a autora defende o ideário de um ensino médio que tenha uma base constituída pela integração entre a perspectiva do trabalho, da ciência e da cultura, com vista a uma formação politécnica, unitária e omnilateral.

Entende-se que o ensino médio realiza uma conexão entre conhecimento e prática do trabalho. Dessa maneira, deve-se proporcionar aos estudantes 0 entendimento dos diferentes princípios técnicos que são empregados no sistema produtivo, e não somente a instrumentalização das técnicas. O que se propõe, na verdade, vai muito além de formar profissionais especializados, mas de formar politécnicos. (RAMOS, 2010).

Pelo exposto até o presente momento, verifica-se que a proposta de um ensino médio integrado à educação profissional está consolidada no ideário de proporcionar aos indivíduos uma formação básica de qualidade, que os forme em sua integralidade. Mas, não deixa de atentar-se ao fato de que essas pessoas, por vezes, também necessitam de uma formação que lhes permita a inserção no mercado de trabalho, ou seja, o ensino profissional.

Também é importante frisar que, ao garantir que esses sujeitos tenham uma formação profissional na etapa do ensino médio, não quer dizer que essa se sobreporá à básica. A formação básica deverá, portanto, possibilitar ao ser humano uma visão ampla de mundo, capaz de torná-lo um ser que pensa e age criticamente em sociedade. Enquanto a profissional dará meios para que aqueles seres humanos que precisam inserir-se logo após a conclusão do ensino médio no mercado de trabalho tenham condições de exercerem funções de nível técnico.

Destaque-se que esses profissionais que serão formados no EMI, que tem a formação unitária como base, não serão técnicos meramente executores de funções, mas sim, serão seres pensantes, que atuam com criticidade. Assim, passam a constituir-se seres humanos capazes de impor suas opiniões, de formar novos conceitos, e o principal, de buscar cada vez mais questionar os modelos que são impostos pelo sistema.

Em suma, a dualidade educacional é fortemente presente na educação brasileira, necessitando de estratégias plausíveis, que possam possibilitar a alteração desse quadro ao invés de intensificá-lo. Em concordância com o entendimento dos 
autores utilizados como aporte teórico, percebe-se que o EMI na perspectiva aqui exposta é um mecanismo de grande relevância para essa transformação.

\title{
4 MOTIVAÇÕES DO INGRESSO NO EMI
}

Ao optar pelo EMI, e, consequentemente, por uma formação profissional, o jovem traça um projeto de futuro, o qual poderá ser dado continuidade ou alterado em decorrência de diversas variáveis. Como Cruz, Pereira e Silva (2014, p. 59) explanam:

\begin{abstract}
Pensar no futuro é um processo que parte do todo ideológico para a parte pensante do indivíduo. Implica necessariamente - em um espaço temporal em formar pensamentos partindo-se do real, perpassando pelo imaginário, até alcançar o real idealizado, prospectado e constituído dentro de uma abstração pessoal, através da convergência das ideologias dominantes.
\end{abstract}

Cruz, Pereira e Silva (2014) apontam que os conflitos ideológicos que perpassam na vida dos estudantes oriundos de escolas públicas, podem interferir na visão que eles têm de seu futuro profissional. Indivíduos esses, que em sua maioria, são atingidos pela desigualdade social e pela competitividade do mundo contemporâneo.

No decorrer das outras seções deste artigo, discorreu-se acerca do papel da integração do ensino básico ao ensino profissional. Como é possível observar, o EMI é visto como uma proposta de formação dos jovens, baseada em uma educação transformadora, sustentada pelo tripé ciência, trabalho e cultura, que forma não apenas para o trabalho, mas para a vida. Como mencionam Cruz, Pereira e Silva (2014, p. 64), "a perspectiva de futuro dos jovens brasileiros depende do ensino e dos valores que lhes são repassados, respeitando-se os seus direitos e peculiaridades individuais, sociais e econômicas".

Para Matos (2016), a presença dos IF por todos os estados brasileiros trouxe o crescimento na oferta do EMI. A autora acrescenta, ainda, que:

Temos, a partir daí, uma nova proposta de escola para um novo jovem sendo ele estudante de uma instituição pública que se destaca por promover avanços imponentes na carreira dos estudantes brasileiros [...], pressupõese que em sua maioria advindos de classes menos favorecidas, cuja formação é uma das poucas perspectivas de saída e crescimento pessoal e profissional. (MATOS, 2016, p. 62). 
Percebe-se que essas instituições têm destaque na oferta dos cursos integrados. Contudo, questiona-se se os estudantes estão escolhendo cursar o EMI conscientes do papel que esse tipo de formação possui para a sociedade. Para uma melhor percepção acerca disso, selecionou-se algumas dissertações, defendidas em programas de pós-graduação em Educação, entre 2016 e 2019, constantes no Banco de Teses da Capes.

Destaque-se que foram selecionados, apenas, trabalhos que trataram especificamente dos cursos do EMI nos IF. Vejamos com mais detalhes:

Matos (2016) desenvolveu uma pesquisa no campus Aracaju do Instituo Federal de Sergipe (IFS) com estudantes do EMI. A autora fez uma abordagem sobre o papel que a escola ocupa na construção dos projetos de futuro dos estudantes jovens. Assim, identificou que os alunos não tinham clareza sobre os aspectos formais do EMI, até mesmo, os que eram concluintes. Constatou-se, ainda, que a escolha por essa modalidade de ensino ocorreu, na maioria dos casos, por incentivos de familiares e/ou amigos. Ao final, concluiu que:

\footnotetext{
Vê-se que a escola, nesse caso o IFS de Aracaju, ocupa para os jovens estudantes do EMI um papel de etapa, nem sempre agradável, pela qual, por imposição burocrática, o jovem tem que passar para chegar à realização dos seus projetos de futuro. Nesse sentido, a escola não ocupa para esses jovens a posição de parte do processo de amadurecimento e formação integral do sujeito, mas de obstáculo, necessidade imposta a eles e que brevemente tem que ser superada, que serve somente para ensiná-los uma profissão provisória como parte de um projeto maior que se consolidará num bom curso universitário e, por fim, no sucesso profissional e, consequentemente, econômico. (MATOS, 2016, p. 111).
}

Para Araújo e Santos (2012), uma "escola não-atrativa" é vista como um dos elementos internos à instituição que mais contribuem para a evasão escolar. Dentre os aspectos que as autoras relacionam a essa falta de atratividade do ambiente escolar estão: falta de apresentação do perfil do curso, das oportunidades no mercado de trabalho, dos critérios e do sistema de avaliação do desempenho do aluno, dentre outros elementos voltados à própria estrutura física e de pessoal.

Veiga (2016), em um estudo acerca dos fatores predominantes da evasão escolar no EMI, identificou que há um consenso entre professores e coordenadores quanto à importância da escolha do curso para a permanência dos estudantes nos cursos. Como relataram os entrevistados, boa parte dos alunos faz a opção pelos cursos, muitas das vezes, por incentivo de terceiros e, consequentemente, não têm conhecimento prévio sobre a formação acadêmica que terão, comprometendo, inclusive, o desempenho escolar do sujeito e, por consequência, leva à evasão escolar. Como principais causas do abando escolar, esses profissionais associam o desinteresse, a dificuldade na aprendizagem, a escolha errada dos cursos e a falta de apoio familiar. 
Veiga (2016) elencou algumas propostas para auxiliar na prevenção do abandono escolar, uma delas refere-se à necessidade de disponibilização, nos certames, de:

[...] um manual orientativo sobre o conteúdo de cada curso ofertado, buscando dirimir dúvidas dos candidatos na escolha de suas carreiras e, com isso, reduzir o número de ingressantes que optam, inconscientemente, por curso cujo conteúdo não condiz com a expectativa esperada. (VEIGA, 2016, p. 79).

Frankiv (2016) desenvolveu um estudo com os estudantes do curso de Contabilidade do Instituto Federal do Paraná (IFPR), buscando identificar os (des)interesses destes com a escola. Em relação aos motivos que os levaram à escolha do curso, constatou-se que muitos dos estudantes escolheram o EMI por incentivos externos, por vezes, de familiares. Expressaram, ainda, que ingressaram no curso sem conhecimento acerca do que ele oferece e qual futuro profissional que se espera diante de tal escolha, desencadeando desinteresse pelo estudo das disciplinas. Acrescentando-se a isso, tem-se o fato de que muitos desses alunos optaram por ingressar no Ensino Superior em áreas distintas do núcleo técnico.

Em pesquisa no Campus São Luís/Maracanã do Instituto Federal do Maranhão, Prado (2017) objetivou investigar as trajetórias escolares dos estudantes do $1^{\circ}$ ano do EMl. Assim, realizou um mapeamento das principais motivações para ingressos nos cursos técnicos. A autora constatou que, apesar de reconhecer a boa avaliação dos cursos, o principal fator motivador para a escolha dos alunos foi o fato da instituição ter prestígio na sociedade. Deixaram claro que, em relação à integração da formação geral e a profissional, preferiam escolher apenas uma. A maioria informou que formação técnica não foi o principal propósito, mas sim o ensino médio, pois não se veem como profissionais técnicos.

Com o estudo voltado para aqueles que ainda não cursaram o EMI, Silveira (2018) utilizou, como locus da pesquisa, um curso preparatório para ingresso no Campus Restinga do Instituto Federal do Rio Grande do Sul. O autor buscou investigar as expectativas dos estudantes que desejavam ingressar no EMI de tal IF. Verificouse que tantos os alunos quanto suas famílias têm expectativas positivas em relação aos cursos do EMI. A motivação está mais voltada para a qualidade da educação que é ofertada na instituição, do que propriamente pelos cursos técnicos. O autor destaca, ainda, que, para alguns dos participantes, ingressar em um IF já se configurava uma conquista.

Diferentemente dos demais autores aqui apresentados, Rodecz (2019) buscou avaliar os motivos que levaram à escolha pelos cursos integrados, por meio do olhar dos jovens egressos. Isso porque, propunha-se avaliar se houve ou não dificuldades na inserção profissional desses. Para isso, a pesquisa foi desenvolvida no Campus Comboriú do Instituto Federal Catarinense. Descobriu-se que a maioria 
optou pelo curso em virtude da qualidade de ensino da instituição, com vistas à inserção no ensino superior. Do total que estavam trabalhando, $82 \%$ não atuam na área do núcleo técnico que frequentaram no IF. Percebeu-se que "o prestígio da instituição e benefícios que isso pode agregar se mostraram superiores ao fator identificação com o curso no processo de escolha". (RODECZ, 2019, p. 108).

Feitosa (2018) procurou identificar se as aspirações dos estudantes do Instituto Federal do Piauí coadunam com os objetivos preconizados para o EMI nos IF. Para tanto, fez-se uma análise das finalidades e objetivos traçados nos documentos oficiais da referida instituição. $\mathrm{O}$ autor percebeu que:

\begin{abstract}
A partir da análise feita, ficou clara a presença de certa insegurança tanto em relação ao futuro, quanto, em alguns casos, relativa a que caminho seguir, considerada, esta insegurança, própria da idade dos alunos e do fato de, nesse momento, estarem diante de dois possíveis caminhos: o do ingresso no mercado de trabalho na área profissional para a qual o curso se propôs a prepará-los e o ingresso no Ensino Superior. Ao mesmo tempo revelam um medo: o de não conseguirem andar por nenhum dos dois caminhos. $\mathrm{Na}$ realidade, de acordo com as respostas deste grupo específico e de acordo com dados históricos levantados pela própria escola ao longo de alguns anos, a maioria dos alunos desse curso busca o ingresso no Ensino Superior. Isso aponta para certo descompasso entre um dos objetivos dos cursos do IFPI que é o da preparação de técnicos de nível médio para o mercado de trabalho, ainda que ultimamente, conforme mostrado no Capítulo 2, o próprio Instituto tem oferecido cursos de nível superior, inclusive para seus egressos do Ensino Médio, criando neles, a par de outros motivadores, esta expectativa. (FEITOSA, 2018, p. 07).
\end{abstract}

Vê-se a importância de a instituição de ensino estar atenta aos aspectos concernentes à visibilidade dos cursos que são ofertados, para possibilitar que os futuros estudantes façam suas escolhas conscientemente. Assim, será possível minimizar os fatores que levam ao desinteresse pela formação escolhida. Como menciona Matos (2016, p. 67-68)

[...] é inerente à escola contribuir com a reflexão dos jovens estudantes sobre a escolha das suas decisões. O que se oferta como ideal da escola reflete inevitavelmente nos horizontes vislumbrados pelos jovens, que, por mais que discordem dos objetivos da escola, têm que se submeter às ofertas educacionais do seu país. Isso implica consequentemente em atitudes e escolhas nem sempre condizentes com o que, de fato almejam para suas vidas e carreiras profissionais.

Como foi demonstrado, os IF são reconhecidos pela sociedade por proporcionarem uma educação de qualidade. Educação essa que é vista pelos Vol. 2 (2020) 
estudantes como uma oportunidade de conquistar a tão sonhada aprovação no ensino superior.

Diante disso, é importante fazer-se um questionamento: será que objetivo da criação dos IF, qual seja, a oferta da educação profissional, não estaria sendo prejudicado, uma vez que uma parcela dos estudantes do EMI demonstram que não têm pretensão de seguir na área escolhida, quer seja, diretamente no mundo do trabalho, quer seja, no Ensino Superior?

\section{CONSIDERAÇÕES FINAIS}

Neste artigo, foi apresentado o contexto histórico da educação profissional no país e, consequentemente, as transformações sofridas pelas instituições que deram origem aos Institutos Federais ao longo dos anos. Assim, um dos caminhos apontados pelos estudiosos apresentados no decorrer do texto que podem oportunizar a superação da dualidade educacional historicamente constituída, destaca-se o EMI que é ofertado nos institutos.

Nesse contexto, entende-se que é necessária a formação de indivíduos que tenham uma base educacional que lhes permita compreender o caráter científico, tecnológico e sócio histórico, para que eles tenham possibilidades de agir em sociedade de forma crítica. Assim, ao pensar-se na construção desse sujeito, é crucial entender que o ambiente escolar tem papel fundamental na formação de cada ser humano. A proposta, conforme autores apresentados no presente texto, é de que se possibilite aos estudantes a formação do ensino básico de forma integrada ao ensino profissional.

Como se expôs, percebe-se que muitos alunos ingressam nos cursos técnicos integrados por influências externas, que são alheias, muitas vezes, a seus projetos de futuro. Isso, mais a frente, conforme esclareceu Veiga (2016), pode levar esses jovens a optarem por abandonar os cursos, por não terem se identificado com eles. Assim, a escola, ao se colocar enquanto um ambiente de formação desses estudantes, necessita compreender que os alunos também precisam se sentir parte do processo. É importante questionar o que esses indivíduos almejam ao escolher determinado curso, para que, assim, seja possível pensar estratégias prévias ao processo decisório destes. Estratégias essas que possibilitem aos estudantes uma amplitude maior sobre cada curso ofertado, fazendo sua escolha conscientemente.

\section{REFERÊNCIAS}

ARAÚJO, C. F.; SANTOS, R. A. A educação profissional de nível médio e os fatores internos/externos às instituições que causam a evasão escolar. In: The 4th International Congress on University- Industry Cooperation, Taubaté, São Paulo, 
05-07, dez, 2012. Disponível em: http://www.unitau.br/unindu/artigos/pdf525.pdf. Acesso em 10 jan. 2020.

BARBOSA, A. C. C. Os Institutos Federais: reflexões sobre a ifetização a partir do processo de elaboração do regimento geral do IFS.1 ed. Aracaju: IFS. 2016.

BRASIL. Decreto $\mathbf{n}^{\circ}$ 2.208, de 17 de abril de 1997. Regulamenta $\circ \S 2 \cong$ do art. 36 e os arts. 39 a 42 da Lei o 9.394, de 20 de dezembro de 1996, que estabelece as diretrizes e bases da educação nacional. Disponível:

http://www.planalto.gov.br/ccivil 03/decreto/D2208.htm. Acesso em: 15 maio. 2019.

BRASIL. Decreto $\mathrm{n}^{\circ}$ 5.154, de 23 de julho de 2004. Regulamenta o $\S 2 \stackrel{0}{ }$ do art. 36 e os arts. 39 a 41 da Lei oㅡ 9.394, de 20 de dezembro de 1996, que estabelece as diretrizes e bases da educação nacional, e dá outras providências. Disponível: http://www.planalto.gov.br/ccivil 03/ ato2004-2006/2004/decreto/d5154.htm. Acesso em: 20 abr. 2019.

BRASIL. Decreto ${ }^{\circ}$ 7.566, de 23 de setembro de 1909. Cria nas capitais dos Estados da República Escolas de Aprendizes Artífices, para o ensino profissional primário e gratuito. Disponível: https://www2.camara.leg.br/legin/fed/decret/19001909/decreto-7566-23-setembro-1909-525411-publicacaooriginal-1-pe.html. Acesso em: 20 abr. 2019.

BRASIL. Decreto-Lei $\mathbf{n}^{\circ}$ 4.127, de 25 de fevereiro de 1942. Estabelece as bases de organização da rede federal de estabelecimentos de ensino industrial. Rio de Janeiro, RJ. Disponível em: https://www2.camara.leg.br/legin/fed/declei/19401949/decreto-lei-4127-25-fevereiro-1942-414123-publicacaooriginal-1-pe.html. Acesso em: 10 maio. 2019.

BRASIL. Decreto-Lei $\mathbf{n}^{\circ}$ 9.613, de 20 de agosto de 1946. Lei Orgânica do Ensino Agrícola. Rio de Janeiro, RJ. Disponível em:

https://www2.camara.leg.br/legin/fed/declei/1940-1949/decreto-lei-9613-20-agosto1946-453681-publicacaooriginal-1-pe.html. Acesso em: 10 maio. 2019.

BRASIL. Lei $\mathbf{n}^{\circ}$ 3.552, de 16 de fevereiro de 1959. Dispõe sobre nova organização escolar e administrativa dos estabelecimentos de ensino industrial do Ministério da Educação e Cultura. Brasília, DF, 1959. Disponível em:

http://www.planalto.gov.br/ccivil_03/LEIS/L3552.htm. Acesso em: 19 abril. 2019.

BRASIL. Lei $\mathbf{n}^{\circ}$ 5.692, de 11 de agosto de 1.971. Fixa Diretrizes e Bases para o ensino de $1^{\circ}$ e $2^{\circ}$ graus, e dá outras providências. Brasília, DF, 1971. Disponível em: http://www.planalto.gov.br/ccivil 03/leis/L5692impressao.htm. Acesso em: 02 maio. 2019. 
BRASIL. Lei $\mathbf{n}^{\circ} \mathbf{7 . 0 4 4}$, de 18 de outubro de 1982. Altera dispositivos da Lei no 5.692 , de 11 de agosto de 1971, referentes a profissionalização do ensino de $2^{\circ}$ grau. Brasília, DF, 1982. Disponível em: http://www.planalto.gov.br/ccivil 03/leis/L7044impressao.htm. Acesso em: 02 maio. 2019.

BRASIL. Lei $\mathbf{n}^{\circ} \mathbf{1 1 . 8 9 2}$, de 29 de dezembro de 2008. Institui a Rede Federal de Educação Profissional, Científica e Tecnológica, cria os Institutos Federais de Educação, Ciência e Tecnologia, e dá outras providências. Brasília, DF, 1982. Disponível em: http://www.planalto.gov.br/ccivil 03/ Ato20072010/2008/Lei/L11892.htm. Acesso em: 02 maio. 2019.

BRASIL/MEC. Concepção e Diretrizes: Instituto Federal de Educação, Ciência e Tecnologia. Brasília, 2008. Disponível em: https://www.poa.ifrs.edu.br/wpcontent/uploads/2010/03/concepcao diretrizes.pdf. Acesso em: 10 jun. 2019.

CIAVATTA, M. A formação integrada: a escola e o trabalho como lugares de memória e de identidade. In: FRIGOTTO, G; CIAVATTA, M; RAMOS, M. Ensino Médio Integrado: Concepções e contradições. 3 ed. São Paulo: Cortez, 2012, p. 83106.

CIAVATTA, M. O ensino integrado, a politecnia e a educação omnilateral: Por que lutamos? Trabalho \& Educação, Belo Horizonte, v. 23, n.1, p. 187-205, jan. /abr. 2014. Disponível em:

http://forumeja.org.br/go/sites/forumeja.org.br.go/files/Ciavatta ensino integrado pol itecnia educacao omnilateral.pdf. Acesso em: 29 abr. 2019.

CHAGAS, S. E. A; MARTINS, L. S.; BARBOSA, F. A. C. Passados presentes nos Institutos Federais Ensino Médio Integrado e as (des) continuidades nas (in)determinações da dualidade estrutural. Revista Unisinos. São Leopoldo, v. 23, p. 559-275, jul. / set., 2019.

CRUZ, V. M. A. C.; PEREIRA, M. F. R.; SILVA, F. F. As Perspectivas de Futuro dos Jovens Frente à Educação Profissional Integrada. Revista de Educação, Ciência e Tecnologia do IFRS. Porto Alegre, v. 1, n. 1, p. 57-72 jan./jun. 2014.

FEITOSA. J. F. Aspirações dos alunos do Ensino Médio Integrado do Instituto Federal do Piauí - Campus Floriano. 2018. Dissertação (Mestrado em Educação). Universidade Nove de Julho, São Paulo, 2018.

FRANKIV, M. A. O (des)interesse dos estudantes do ensino médio integrado em uma instituição federal de ensino. 2016. Dissertação (Mestrado em Educação). Universidade Federal do Paraná, Curitiba, 2016. 
FRIGOTTO, G; CIAVATTA, M; RAMOS, M (org.). Ensino Médio Integrado: Concepções e contradições. 3 ed. São Paulo: Cortez, 2012.

MATOS, E. F. R. Histórias Planejadas? Uma análise sobre "juventudes", escola e projetos de futuro no ensino médio integrado do IFS em Aracaju. Dissertação (Mestrado em Educação). Universidade Federal de Sergipe. Aracaju, p. 131. 2016.

MOURA, D. H. Ensino Médio e educação profissional: dualidade histórica e possibilidades de integração. In: Moll, J. e colaboradores. Educação Profissional e Tecnológica no Brasil Contemporâneo: desafios, tensões e possibilidades. Porto Alegre: Artmed, 2010. p. 58-79.

PRADO, R. M. M. O. Investigando trajetórias escolares na formação profissional técnica de nível médio: o caso IFFMA - Campus Maracanã. 2017. Dissertação (Mestrado em Educação), Universidade Federal do Rio de .Janeiro, Rio de Janeiro, 2017.

RAMOS, M. N. Ensino Médio Integrado: ciência, trabalho e cultura na relação entre educação profissional e educação básica. In: Moll, J. e colaboradores. Educação Profissional e Tecnológica no Brasil Contemporâneo: desafios, tensões e possibilidades. Porto Alegre: Artmed, 2010. p. 42-56.

RAMOS, M. N. Ensino Médio Integrado: lutas históricas e resistências em tempos de regressão. In: ARAÚJO, A. C.; SILVA, C. N. N. (org.). Ensino Médio Integrado no Brasil: Fundamentos, Práticas e Desafios. Brasília: ed. IFB, 2017. p. 20-43. E-book. Disponível em:

http://www.anped.org.br/sites/default/files/images/livro completo ensino medio inte grado - 1310 2017.pdf. Acesso em: 20 abr. 2019.

RAMOS, M. N. Ensino Médio Integrado da conceituação à operacionalização. Cadernos de Pesquisa em Educação, Vitória, a.11, v. 19, p. 15-29, jan. /jun. 2014a. Disponível em: http://periodicos.ufes.br/educacao/article/view/10243/7029. Acesso em: 29 abr. 2019.

RAMOS, M. N. História e política da educação profissional. Curitiba: Instituto Federal do Paraná, 2014b. E-book. Disponível em: http://curitiba.ifpr.edu.br/wpcontent/uploads/2016/05/Hist\%C3\%B3ria-e-I. Acesso em: 30 abr. 2019.

RODECZ. M. Juventude(s): Escolha e Inserção Profissional Dos Jovens Egressos Do Ensino Médio Integrado. 2019. Dissertação (Mestrado em Educação). Universidade do Vale do Itajaí, Itajaí, 2019.

SILVEIRA, C. E. A. da. Expectativas de estudantes do $9^{\circ}$ ano no ensino fundamental em relação ao ensino médio integrado no Instituto Federal do Rio 
Grande do Sul - Campus Restinga. 2018. Dissertação (Mestrado em Educação). Universidade Federal do Rio Grande do Sul, Porto Alegre, 2018.

VEIGA, C. R. Fatores predominantes da evasão escolar no ensino médio integrado: uma proposta de estratégia de prevenção para o CEFET/RJ. Dissertação (Mestrado em Sistema de Gestão). Universidade Federal Fluminense. Escola de Engenharia, p. 103. 2016. 